\title{
PERFIL GRÁFICO DAS PINTURAS RUPESTRES PRÉ-HISTÓRICAS DO VALE DO MOXOTÓ BRASIL
}

\section{Ricardo Barbosa ${ }^{*}$}

Demétrio Mutzenberg ${ }^{* *}$

Daniela Cisneiros $^{* *}$

\footnotetext{
* Doutor em Arqueologia pela Universidade Federal de Pernambuco - UFPE

** Docente do Departamento de Arqueologia da Universidade Federal de Pernambuco - UFPE.
}

RESUMO: Essa pesquisa é resultado da análise de 143 representações humanas pré-históricas pintadas, circunscritas nos sítios arqueológicos do Vale do Moxotó e do quadrante nordeste da Bacia Hidrográfica do Pajeú. O estudo foi realizado com a utilização do Quadro Analítico do Fenômeno Gráfico que, enquanto ferramenta metodológica, propõe que o fenômeno gráfico seja analisado em três dimensões, distintas entre si, mas que se interligam e se completam: Temática; Cenográfica; e Técnica. A escolha das categorias foi orientada para cumprir um duplo objetivo: apontar o perfil gráfico regional e efetuar comparações análogas entre os perfis já definidos para o Nordeste do Brasil. A pesquisa resultou na indicação de três padrões cenográficos que podem ser indicados como perfis para o Vale do Moxotó. Os dados, coletados de acordo com a metodologia proposta para o estudo, apontam proximidade técnica e cenográfica dos perfis gráficos delineados para o Vale do Moxotó e os definidos para a Região do Seridó.

Palavras-chave: Pintura rupestre; Perfil gráfico; Vale do Moxotó; Vale do Catimbau.

ABSTRACT: This research analyzes 143 prehistoric painted human representations circumscribed in archaeological Valley of Moxotó and the northeast quadrant of the Pajeú Basin. The study was conducted using the Analytical Framework that while methodological tool, proposes that the graphic phenomenon is analyzed in three dimensions, distinct from each other, but that interlock and are complementary: thematic, scenic and technical. The choice of the categories was guided to fulfill two objectives: regional point the graphic profile, and make similar comparisons between the profiles already defined for the Northeast of Brazil. The research resulted in the appointment of at least three patterns scenography that can be displayed as profiles for Moxotó Valley. The data, collected according to the methodology proposed for the study, indicate the proximity of technical and scenic graphic profiles outlined for Moxotó Valley and defined for the Seridó Region.

Keywords: Rock art, Graphic profile; Moxotó Valley; Catimbau Valley 


\section{Introdução}

A presente pesquisa teve como objeto de estudo as representações humanas pré-históricas circunscritas nos sítios arqueológicos do Vale do Moxotó e do quadrante nordeste da Bacia Hidrográfica do Pajeú. Ambas as regiões estão inseridas na zona de domínio morfoclimático da caatinga. Todavia, os sítios estudados estão ambientados nas áreas geomorfologicamente denominadas de 'brejo de altitude' ou em locais sob sua influência direta. Estes sítios encontram-se irregularmente distribuídos nos municípios de Afogados da Ingazeira, Buíque e Ibimirim.

A escolha do Vale do Moxotó como área nuclear dessa pesquisa é duplamente justificada, tanto do ponto de vista do seu posicionamento geográfico como do ponto de vista da dispersão de um grupo particular de pintura, a classe inicial denominada Tradição Nordeste de pintura rupestre, que, frente aos dados até então obtidos, teve início no sudeste do Piauí. A região estudada encontra-se entreposta às áreas arqueológicas da Serra da Capivara (PI) e do Seridó (RN / PB); e entre os vales do São Francisco e do Açú-Piranhas, do qual o Rio Seridó é tributário.

O resultado da pesquisa aponta a existência de uma proximidade técnica e cenográfica do perfil gráfico da região estudada com as pinturas da Serra da Capivara e do Seridó; também permite a segregação de três perfis gráficos ${ }^{1}$ para o Vale do Moxotó, como segue: um grupo de figura tem os membros superiores e inferiores representados por linhas finas, retilíneas e posicionadas em ângulos; outro grupo de figuras, sem causar qualquer tipo de prejuízo daquilo que é encenado, tem a cabeça suprimida ou oculta por máscara; um terceiro grupo de figuras apresenta cavidade facial, cuja morfologia remete ao estilo Carnaúba.

\section{A Pesquisa}

A pesquisa ora apresentada foi desenvolvida com duplo propósito: a) identificar e apresentar o perfil (ou perfis) gráfico do Vale do Moxotó, a partir das características gerais das representações humanas; b) realizar comparações entre o perfil gráfico da região estudada e os outros perfis já definidos para o Nordeste do Brasil. Espera-se, ao se atingir os objetivos delineados, reunir elementos que permitam inferir sobre as possíveis relações culturais entre os autores dos grafismos do Vale do Moxotó e os pintores da Serra da Capivara e do Seridó.

A conduta em campo foi guiada para a busca e sistematização dos dados que pudessem gerar informações que embasassem as respostas para os problemas levantados para a região estudada: a) Qual o perfil (ou perfis) gráfico do Vale do Moxotó e sua área contígua, o quadrante nordeste da Bacia do Pajeú. b) Como se comportam ou como estão inseridas as

\footnotetext{
${ }^{1}$ Trata-se de uma estruturação sistêmica de atributos flexíveis (categorias de entrada), hierarquizados segundo menor grau de ambiguidade, orientados, em linhas gerais, no sentido de segregar as características próprias do acervo gráfico (marcadores de identidade) de uma determinada área.
} 
figuras antropomorfas num ambiente de brejo de altitude, com importante amplitude entre a mínima e a máxima cota altitudinal? c) Há proximidade técnica e cenográfica entre o perfil verificado no Vale do Moxotó e os perfis já estabelecidos para o Nordeste do Brasil? d) Diante de uma possível proximidade técnica e cenográfica destes perfis, pode se pensar numa vinculação cultural entre eles?

O perfil gráfico do Vale do Moxotó foi definido, metodologicamente, a partir das características gerais das representações humanas que se enquadrassem, num primeiro plano, em critérios sensoriais do reconhecimento pleno da condição humana e que, num segundo plano, se enquadrassem em determinados critérios técnicos de execução e, por derradeiro, que expressassem uma dinâmica corporal, conforme detalhamento:

a) critérios sensoriais - $\mathrm{O}$ reconhecimento da figura antropomorfa foi realizado a partir da observação de elementos básicos da identidade humana, como a presença da cabeça, do tronco e dos membros ou, pelo menos, a existência de parte dos elementos que a identifique como tal;

b) critérios técnicos de execução - Dentre os critérios técnicos de execução foi considerado aquele que aponta para a acuidade técnica, como a precisão dos contornos externos das figuras e a ausência de sinais de escorrimento de tinta;

c) movimento - Movimento expresso na dinâmica corporal da figura.

O perfil gráfico para o Vale do Moxotó foi estabelecido tomando como base a utilização do Quadro Analítico de Pessis (1992), que, enquanto ferramenta metodológica, propõe o estudo do fenômeno gráfico em três dimensões, distintas entre si, mas que se interrelacionam e se complementam: Temática; Cenográfica; e Técnica. Para essa pesquisa, no estudo do Vale do Moxotó, no âmbito da Dimensão Temática, foram utilizadas duas variáveis: representação humana; e atributo cultural associado. Na Dimensão Cenográfica foram instituídas as categorias: morfologia; movimento; composição; tamanho; preenchimento; e cor. E na Dimensão Técnica foram utilizadas as categorias: tratamento do suporte; e espessura do traço.

As diversas etapas de desenvolvimento da pesquisa foram orientadas pela hipótese de trabalho estabelecida para a região: 'O Vale do Moxotó constitui uma área de intersecção gráfica'. A referida hipótese apoia-se em duas importantes proposições: a) o posicionamento geográfico do Moxotó, entreposto a Serra da Capivara e a região do Seridó; b) e a existência de um corpus gráfico composto por pinturas cujos perfis gráficos demonstram, preliminarmente, proximidade técnica e cenográfica com os perfis já estabelecidos para o Nordeste do Brasil.

\section{Resultados}

\section{Os Perfis Gráficos}

Resultam do estudo das representações humanas, cujas características mais gerais são o seu preenchimento com tinta vermelha $(95,80 \%)$ e projeção em tamanho reduzido $(59,44 \%$ no intervalo entre 5,1 e $15 \mathrm{~cm}$ ), o surgimento de, pelo menos, três padrões cenográficos que podem ser indicados como perfis para o Vale do Moxotó: 
a) Um grupo de figuras tem os membros superiores e inferiores representados por linhas finas, retilíneas e posicionadas em ângulos: ora obtuso; ora reto; ora oblíquo (Figura 1)

b) Outro grupo de figuras tem a cabeça suprimida ou oculta por máscara (Figura 2)

c) Outro grupo de figuras apresenta cavidade facial, cuja morfologia remete à ao estilo Carnaúba (Figuras 3 e 4).
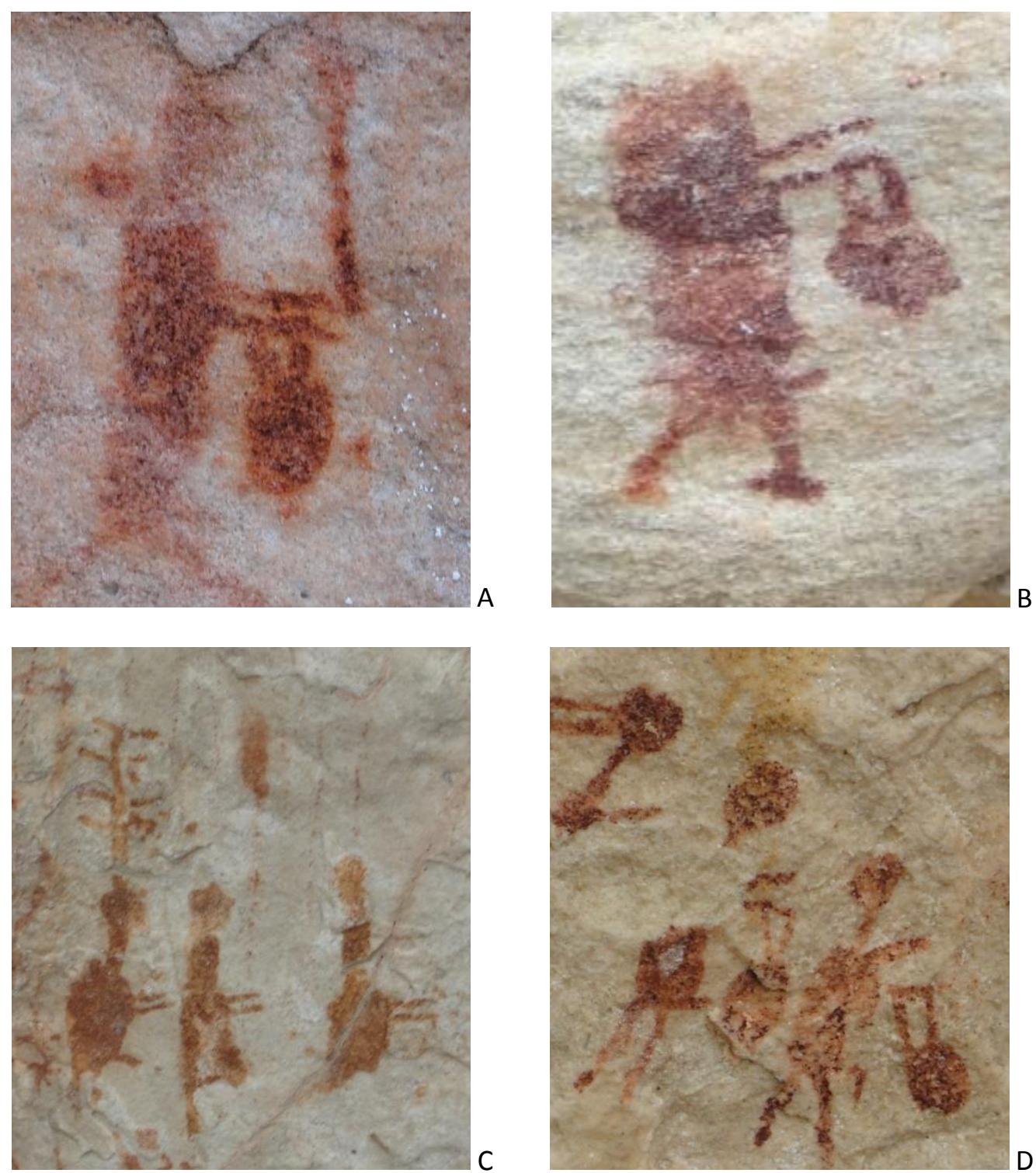

Figura 1: Figuras com os membros superiores e inferiores representados por linhas finas, retilíneas e posicionadas em ângulos. A) Sítio Tauá l; B) Loca dos Caboclos; C) Loca da Cinza; D) Loca da Cinza 

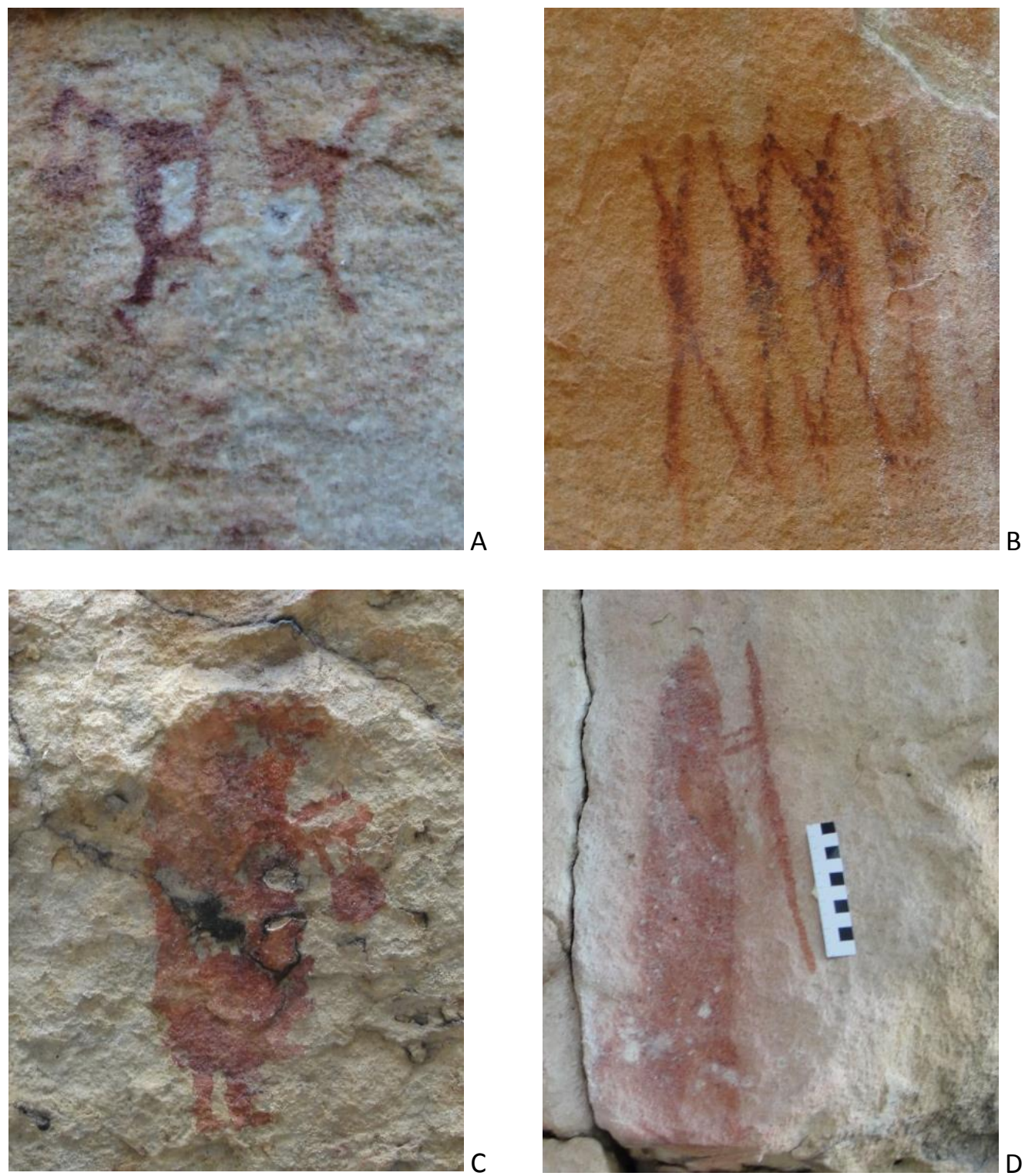

Figura 2: Figuras com a cabeça suprimida ou oculta por espécie de máscara. A) Loca dos Caboclos; B) Pedra do Giz; C) Loca dos caboclos; D) Sítio Guardião 


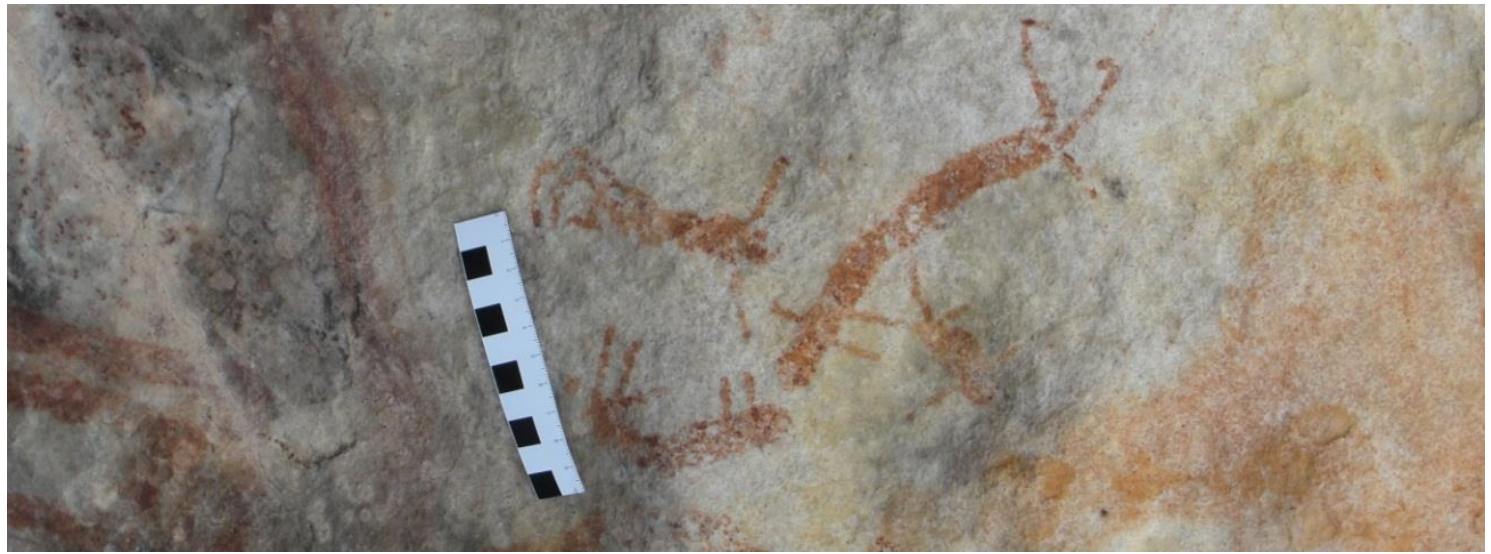

Figura 3: Sítio Loca da Cinza; detalhe da cavidade facial

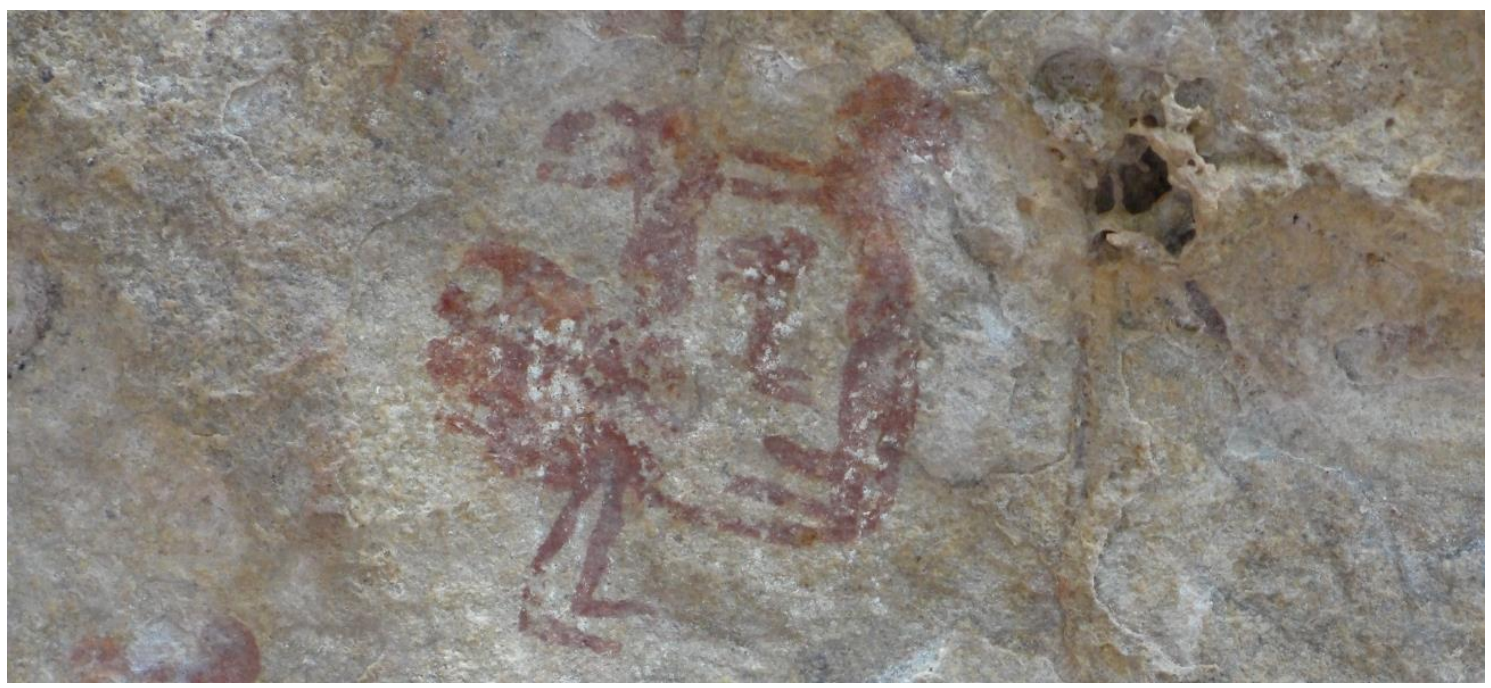

Figura 4: Sítio Tauá II; detalhe da cavidade facial

\section{As Homologias}

Na comparação gráfica entre as figuras do Vale do Moxotó e do Seridó foram utilizadas as seguintes categorias analíticas: forma de apresentação dos membros; composição anatômica; cavidade facial; e atributo cultural associado.

Quanto ao estudo da forma de apresentação dos membros, os dados referentes à Região do Seridó revelaram que $45,45 \%$ dos braços das figuras foram representados de forma retilínea; e $38,65 \%$, de forma antinatural, curvada; e, apenas, 4,54\% de forma flexionada. O formato 'linha reta' também foi utilizado, preferencialmente, para representar as pernas das figuras, com $60,18 \%$ dos casos; $26,14 \%$ com o formato 'curvado'; e $2,27 \%$ com o formato 'flexionado'. Frente aos dados levantados para a comparação, pode-se assegurar que os formatos 'linha reta', 'linha curvada' e 'linha flexionada' são utilizados pelos pintores tanto do Vale do Moxotó como da Região do Seridó para representar os membros das figuras humanas. Contudo, a linha reta mostra-se dominante, enquanto forma de representar braços e pernas, em ambas as regiões. 
Em relação à composição anatômica, o estudo apontou que 79,54\% das figuras ambientadas no Seridó têm anatomia corporal completa e $20,46 \%$ incompleta. Das figuras com anatomia incompleta, a supressão da cabeça representa 5,68\% dos casos; e $11,36 \%$ têm a representação dos braços suprimida, e 3,41\% têm ausência de pernas. Os dados pertinentes à composição anatômica comparada permitem concluir que: a economia de traços é uma característica comum aos acervos gráficos do Moxotó e Seridó; entretanto, a ausência da cabeça é, em termos estatísticos, mais expressiva no Vale do Moxotó.

Em relação ao estudo comparativo da cavidade facial, este detalhe anatômico está presente em 14,16\% das figuras do Moxotó e 31,81\% das figuras do Seridó.

O estudo dos atributos culturais associados demonstra que estes elementos aparecem, em $52,27 \%$ das figuras selecionadas do Seridó, os seguintes adereços: os utensílios (cestos ou sacolas) representam $27,27 \%$ dos casos, seguidos dos bastões $(15,91 \%)$, dos cocares $(9,09 \%)$ e das vestes $(3,40 \%)$. Das figuras representadas com atributo cultural 9,09\% apresenta duplo adereço associado, foram observadas as seguintes combinações: cocar + vestimenta $(1,37 \%)$; bastão + utensílio (6,82\%); bastão + bastão (1,37\%). Os dados pertinentes a este item da análise comparativa permitem concluir que há proximidade cenográfica das figuras do Moxotó com as do Seridó, considerando a forma como estes adereços foram dispostos nas figuras, assim como, na forma de combinar os diversos adereços (Figura 5).

Vale salientar que as categorias de análise referentes ao estudo comparativo não foram aplicadas às figuras atribuídas ao estilo Serra da Capivara II; fato justificado pela ausência deste tipo de representação na amostra de figuras potiguares selecionadas para o estudo. Dentre as figuras pertencentes ao citado estilo, minoritárias no conjunto de figuras pernambucanas, foram identificadas: três representações humanas $(2,10 \%)$ no Sítio Loca da Cinza (Buíque); e um veado galheiro no Sítio Pedra do Giz (Afogados da Ingazeira). Esse zoomorfo, identificado no Sítio Pedra do Giz, está sobreposto por um antropomorfo similar ao estilo Carnaúba.

Em suma: os dados, coletados de acordo com a metodologia proposta para o estudo, permitem assegurar a proximidade técnica e cenográfica dos perfis gráficos delineados para o Vale do Moxotó e os definidos para a Região do Seridó. 


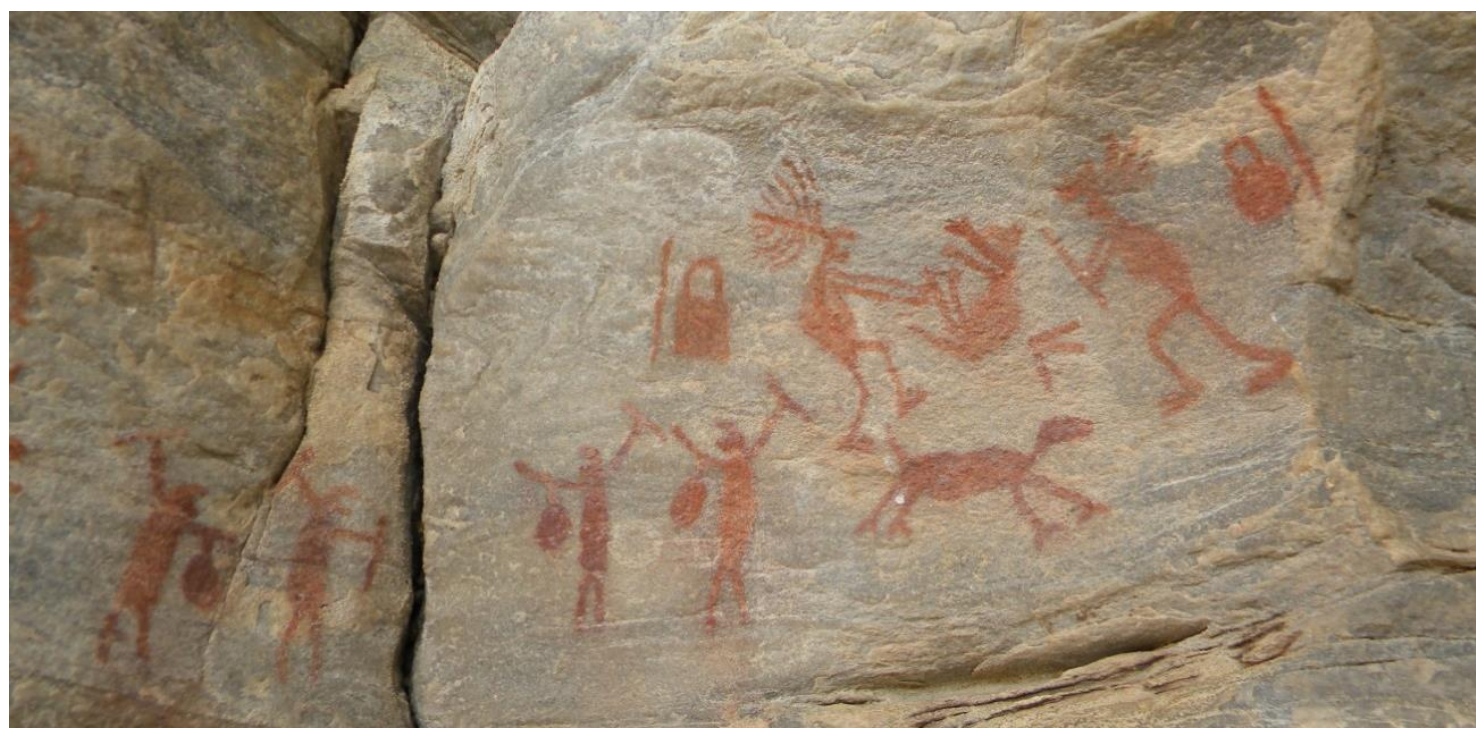

Figura 5: Sítio Xique-Xique I. Foto: acervo gráfico da Fundação Seridó.

\section{Considerações Finais}

Como mencionado, esse trabalho foi realizado com os propósitos: a) identificar o perfil gráfico do Vale do Moxotó, com a intenção de efetuar comparações homólogas entre os perfis definidos para o Nordeste do Brasil; b) e, reunir dados factíveis que inscrevam a região estudada como Área de Intersecção Gráfica, hipótese de trabalho que norteou todo desenvolvimento da pesquisa.

Os dados coletados, segundo a metodologia proposta, permitem concluir que há proximidade técnica e cenográfica entre os perfis delineados para o Vale do Moxotó e o Seridó. Mas, a identificação de tal proximidade permite, apenas, deixar no campo hipotético a origem comum dos grupos pintores; contudo, pode-se assegurar que a cultura gráfica verificada no Seridó estende-se para além de suas fronteiras geográficas, atingindo o Vale do Moxotó.

Quanto à hipótese de trabalho, os dados apoiam a instituição do Vale do Moxotó como Área de Intersecção Gráfica. Fato calcado na identificação de distintos conjuntos de pinturas no interior do vale, a saber: um assimilável ao estilo Serra da Capivara II; outro, atribuível ao estilo Carnaúba; e, um terceiro conjunto, que reúne características do estilo Carnaúba (cara de caju), mas exibe algumas particularidades, próprias da região estudada.

O terceiro conjunto de figuras tem os movimentos corporais mais contidos que os verificados no acervo do Seridó, alude uma tendência ao enrijecimento; também é particular a forma como foi representado o rosto, com uma cavidade facial que a remete ao estilo Carnaúba (cara de caju). Mas, esta cavidade apresenta-se com a abertura menor que a verificada no acervo gráfico do Seridó. No Moxotó a cavidade, na sua máxima extensão, chega a ocupar até $2 / 3$ da face; enquanto no Seridó, esta cavidade tende a ocupar a face inteira.

Do ponto de vista temporal, no Sítio Pedra do Giz uma figura típica do Moxotó encontra-se sobreposta à outra figura do estilo Serra da Capivara II; esta sobreposição, enquanto referente 
temporal não-cronológico, indica a anterioridade da execução técnica da figura atribuída ao estilo Serra da Capivara II e a sucessão da figura do 'tipo Moxotó'. Entretanto, este referente temporal, único em todo área pesquisada, mostra-se insuficiente para se concluir sobre a sucessão de estilos. Mas, pode servir de ponto de partida para novas pesquisas na região.

\section{Referências}

MARTIN, G. Pré-história do Nordeste do Brasil. Editora Universitária/UFPE, Recife, 3ed, 1999.

PESSIS, A-M. Da antropologia visual à antropologia pré-histórica. Clio Arqueológica, Recife, n. 3, p. 153161,1986

PESSIS, A-M. Apresentação gráfica e apresentação social na Tradição Nordeste de pintura rupestre do Brasil. Clio Arqueológica, Recife, n. 5, 11- 18, 1989.

PESSIS, A-M. Contexto e apresentação social dos registros visuais na antropologia pré-histórica. Clio Arqueológica, Anais do I simpósio de pré-história do nordeste brasileiro, Recife, n. 4, p. 133- 134, 1991.

PESSIS, A-M. Identidade e classificação dos registros gráficos pré-históricos do nordeste do Brasil. Clio Arqueológica, Recife, n. 8, p. 35- 68, 1992.

PESSIS, A-M. Imagens da pré-história. São Paulo: FUMDHAM - PETROBRÁS, 2003.

PESSIS, A-M. A Transmissão do saber na arte rupestre do Brasil. In: Antes: histórias da pré- história. Rio de Janeiro: Fundação Banco do Brasil, 2004, p. 142- 163.

PESSIS, A-M. Arqueologia de gênero: teoria e fato arqueológico. Clio Arqueológica, Recife, n. 18, p. 1125, 2005.

PESSIS, A-M et al. Prospecção arqueológica de sítios com registros rupestres na Chapada do Araripe. Clio Arqueológica, Recife, n. 18, 123- 140, 2005.

PESSIS, Anne-Marie; GUIDON, Niède. Ars indígina pré-histórica do Brasil. Clio Arqueológica, Anais da X Reunião Científica da SAB (UFPE - 2000), Recife, n. 14, 135- 141, 2000.

República Federativa do Brasil, Brasília, DF, n. 58, 23 out. 2006. Seção I, p. 84. 